\title{
Application of an education model using the WeChat public platform in the standardized training of anesthesiology residents
}

\author{
Lina Huang", Guanghui An", Shan You, Shiwei Huang, Jinbao Li \\ Department of Anesthesiology, Shanghai General Hospital, Shanghai Jiao Tong University School of Medicine, Shanghai, China \\ Contributions: (I) Conception and design: G An; (II) Administrative support: G An; (III) Provision of study materials or patients: L Huang; (IV) \\ Collection and assembly of data: L Huang; (V) Data analysis and interpretation: All authors; (VI) Manuscript writing: All authors; (VII) Final \\ approval of manuscript: All authors. \\ \#These authors contributed equally to this work. \\ Correspondence to: Jinbao Li. No. 86 Wujin Road, Hongkou District, Shanghai, China. Email: lijinbaoshanghai@163.com.
}

\begin{abstract}
Background: Standardized training of clinical residents is an important way to train high-level clinicians and is an important step to ensure quality clinical work. WeChat facilitates efficient information dissemination and feedback, convenient communication. In the new media era, the influence of WeChat has inspired changes in educational methods, to explore the role of an education model using the WeChat public platform in the standardized training of anesthesiology residents.

Methods: A total of 40 anesthesiology residents undergoing standardized training in our department from January 2016 to August 2017 were selected as subjects and randomly divided into 2 groups: traditional group ( $n=20)$ and WeChat group $(n=20)$. In the WeChat group, in addition to the traditional clinical teaching model (lectures), the residents also received push information from the WeChat public platform for anesthesia education. The residents in the traditional group did not receive the push information and only received traditional clinical teaching. Three months later, assessment scores of and teaching quality in the 2 groups were evaluated. Teaching quality was evaluated using peer assessment and self-assessment questionnaires.

Results: Residents in the WeChat group performed significantly better on assessments than those in traditional group regarding theoretical knowledge of anesthesiology, understanding mechanisms, operation ability, current knowledge, case analyses and use of professional English $(\mathrm{P}<0.05)$. The questionnaire results indicated that the degree of satisfaction of the residents and teachers in the WeChat group was significantly higher than that in the traditional group $(\mathrm{P}<0.05)$. The theoretical knowledge scores, operational skill scores and overall scores in the WeChat group were significantly higher than those in the traditional group $(\mathrm{P}<0.05)$. Conclusions: Applying an education model based on the WeChat public platform in standardized training of anesthesiology residents can significantly improve teaching efficacy and satisfaction, enhance comprehensive assessment results, and improve teaching quality.
\end{abstract}

Keywords: WeChat; anesthesiology; standardized training of residents

Submitted Oct 20, 2019. Accepted for publication May 21, 2020.

doi: 10.21037/apm-19-390

View this article at: http://dx.doi.org/10.21037/apm-19-390

\section{Introduction}

Standardized training of clinical residents is an important way to train high-level clinicians and is an important step to ensure quality clinical work. At present, as the standardized training system for residents has gradually progressed throughout the country, the advantages of this system have gradually become prominent (1).

Anesthesiology is a high-risk and highly practical discipline. During the process of training anesthesiologists, the understanding and application of knowledge and 
the accumulation of clinical experience are key factors that determine the quality of an anesthesiologist. There are many issues related to improving teaching in the standardized training of anesthesiology residents in teaching hospitals in China. Such as residents who participate in standardized training also undertake heavy clinical work. Therefore, effectively studying and being familiar with current knowledge while involved in heavy clinical work is a challenging task.

As a web application platform featuring interpersonal communication, WeChat facilitates efficient information dissemination and feedback, convenient communication and collaboration and sharing, moderate interaction distance, etc., and has quickly become the top communication app (2), making it a breakthrough technology for educational and teaching reform $(3,4)$. Combining WeChat with education is the focus of current educators (5).

Through a survey, we introduced an education model based on the WeChat public platform to the residents of the Department of Anesthesiology in our hospital; the model achieved good results and significantly improved teaching quality and teaching satisfaction.

\section{Methods}

\section{Establishment of a WeChat public platform for anesthesia education}

A WeChat public platform for anesthesia education was established for 6 topics: current knowledge updates, case discussions, professional knowledge in anesthesiology, professional English in anesthesiology, literature reviews and visualization of anesthesia; the content was pushed every morning to the residents in the standardized training so they could access the information at any time during the day for supplemental reading and learning.

Knowledge updates included newly published clinical guidelines, major clinical research results and new knowledge of guiding significance for clinical work. Case discussions included typical cases encountered during clinical work and interesting cases provided by teachers. These cases were shared with the residents. Additionally, a WeChat group was established to allow communication and comments by residents in a timely manner. The comments of each resident were summarized in order to find deficiencies in the management of clinical cases. Based on Miller's Anesthesia and Clinical anesthesiology by G. Edward Morgan Jr et al., professional knowledge in anesthesiology was pushed daily to strengthen the learning. Based on the English versions of Miller's Anesthesia and Clinical anesthesiology by G. Edward Morgan Jr. et al., guidance on professional English in anesthesiology was pushed every day to help residents learn and improve their professional English and vocabulary. Literature reviews and recent classic articles in professional journals of anesthesia, such as Anesthesia \& Analgesia, British Fournal of Anaesthesia, European Fournal of Anaesthesiology and Pain, were shared with residents and were articles with farreaching significance to clinical anesthesia and scientific research regarding anesthesia. Visualization of anesthesia, which has had a significant impact on anesthesia work in recent years, was a special topic. The content was pushed by means of multimedia presentations, including audio, video, and pictures, so as to provide residents with abundant learning materials for repeated review.

\section{Study participants, grouping and evaluation methods}

A total of 40 anesthesiology residents undergoing standardized training in our department from January 2016 to August 2017 were selected as participants, all the residents have signed informed consents, and randomly divided into 2 groups: traditional group $(\mathrm{n}=20)$ and WeChat group $(n=20)$. In the WeChat group, in addition to the traditional clinical teaching model (lectures and practice), the residents also received push information from the WeChat public platform for anesthesia education. The residents in the traditional group did not receive push information and only received traditional clinical teaching. Three months later, assessment scores of and teaching quality in the 2 groups were evaluated.

\section{Teaching effectiveness using the WeChat public platform}

Teaching effectiveness was evaluated by means of a questionnaire. Quality was assessed using a teaching quality questionnaire. The questionnaire included 6 items for both peer assessment and self-assessment, including mastering of theoretical knowledge and mechanisms in anesthesiology, operational ability, mastering of current knowledge, case analysis skills and professional English level. A 4-point [0-3] grading method was adopted: 0 bad; 1 ordinary; 2 good; 3 , great. The total score of the self-assessment was 18 points, and the total score of the peer assessment was 18 points. In addition, the degree of satisfaction with teaching, as assessed by residents and teachers, was calculated. In addition, using the assessment criteria, the residents were evaluated after 
Table 1 Teaching quality questionnaire (self-assessment) $(\bar{x} \pm \mathrm{s})$

\begin{tabular}{|c|c|c|c|c|c|c|c|}
\hline Group & $\begin{array}{l}\text { Theoretical } \\
\text { knowledge }\end{array}$ & $\begin{array}{l}\text { Understanding } \\
\text { mechanisms }\end{array}$ & $\begin{array}{l}\text { Operational } \\
\text { ability }\end{array}$ & $\begin{array}{c}\text { Current } \\
\text { knowledge }\end{array}$ & Case analysis & $\begin{array}{c}\text { Professional } \\
\text { English }\end{array}$ & Total score \\
\hline WeChat group & $2.5 \pm 0.6^{\star}$ & $2.2 \pm 0.6$ & $2.4 \pm 0.3$ & $2.3 \pm 0.4^{\star}$ & $2.0 \pm 0.3^{*}$ & $2.0 \pm 0.3^{*}$ & $13.3 \pm 0.6^{\star}$ \\
\hline Traditional group & $2.2 \pm 0.5$ & $2.0 \pm 0.6$ & $2.1 \pm 0.4$ & $1.9 \pm 0.5$ & $1.5 \pm 0.4$ & $1.5 \pm 0.4$ & $10.4 \pm 0.5$ \\
\hline
\end{tabular}

The results of the teaching quality questionnaire (self-assessment) in the Wechat teaching group and, traditional group, including the mastering of theoretical knowledge and mechanisms in anesthesiology, operational ability, mastering of current knowledge, case analysis skills and professional English level. Level A 4-point [0-3] grading method was adopted: 0, bad; 1, ordinary; 2, good; 3, great. *, compared with the traditional group, $\mathrm{P}<0.05$.

Table 2 Teaching quality questionnaire (peer assessment) $\left(\bar{x}_{ \pm s}\right)$

\begin{tabular}{|c|c|c|c|c|c|c|c|}
\hline Group & $\begin{array}{l}\text { Theoretical } \\
\text { knowledge }\end{array}$ & $\begin{array}{l}\text { Understanding } \\
\text { mechanisms }\end{array}$ & $\begin{array}{l}\text { Operational } \\
\text { ability }\end{array}$ & $\begin{array}{c}\text { Current } \\
\text { knowledge }\end{array}$ & Case analysis & $\begin{array}{l}\text { Professional } \\
\text { English }\end{array}$ & Total score \\
\hline WeChat group & $2.3 \pm 0.6^{\star}$ & $2.1 \pm 0.5$ & $2.3 \pm 0.3$ & $2.3 \pm 0.5^{\star}$ & $2.0 \pm 0.5^{\star}$ & $1.9 \pm 0.3^{*}$ & $12.8 \pm 0.7^{\star}$ \\
\hline
\end{tabular}

The results of the teaching quality questionnaire (peer assessment) in the Wechat teaching group and, traditional group, including the mastering of theoretical knowledge and mechanisms in anesthesiology, operational ability, mastering of current knowledge, case analysis skills and professional English level. Level A 4-point [0-3] grading method was adopted: 0, bad; 1, ordinary; 2, good; 3, great. *, compared with the traditional group, $\mathrm{P}<0.05$.

three months of standardized training; the assessment included 2 items: mastering of the theoretical knowledge and operational skills. The assessment was performed by a team established by the senior anesthesiologists of our hospital, with 100 points (0-100) for each item.

Overall score $=($ Assessment of mastering of the theoretical knowledge \& Assessment of operational skills)/2.

\section{Statistical analysis}

SPSS 15.0 was used for the statistical analysis of the numerical data. Measurement data are expressed as (mean $\pm \mathrm{SD}$ ). The t-test was used for intergroup comparisons, and $\mathrm{P}<0.05$ was considered statistically significant.

\section{Results}

\section{Questionnaire results}

Based on the assessment results, the residents in WeChat group performed significantly better than those in traditional group in terms of learning theoretical knowledge in anesthesiology, understanding the mechanisms, operational ability, current knowledge, case analysis ability and use of professional English $(\mathrm{P}<0.05$, Tables 1,2). Self- assessment results showed that the degree of satisfaction of residents in the WeChat group was $(86 \pm 11) \%$ while that in the traditional group was $(74 \pm 15) \%$; there was a significant statistical difference between the 2 groups $(\mathrm{P}<0.05)$. For teaching effectiveness, the results of the peer assessment indicated that in the WeChat group, the satisfaction of teachers was $(82 \pm 6) \%$; in the traditional group, the satisfaction of teachers was $(72 \pm 7) \%$. There was a significant statistical difference between the 2 groups $(\mathrm{P}<0.05)$.

\section{Assessment results}

The theoretical knowledge scores, operational skill scores and overall scores in the WeChat group were significantly higher than those in the traditional group $(\mathrm{P}<0.05$, Table 3$)$.

\section{Conclusions}

The education model based on the WeChat public platform in standardized training of anesthesiology residents can significantly improve teaching efficacy and satisfaction, enhance comprehensive assessment results, and improve teaching quality

For the first time, this study applied an education model 
Table 3 The assessment score of the residents in both group $(\bar{x} \pm s)$

\begin{tabular}{lccc}
\hline Group & Theoretical knowledge score & Operational skill score & Overall score \\
\hline WeChat group & $92.3 \pm 6.7^{*}$ & $91.8 \pm 5.5$ & $92.1 \pm 6.0^{*}$ \\
Traditional group & $81.9 \pm 7.8$ & $82.3 \pm 6.2$ & $82.1 \pm 6.8$ \\
\hline
\end{tabular}

The assessment score of the residents in mastering of the in Theoretical knowledge and Operational skill both groups. 0-100 points (0-100) for each item. Overall score $=($ Assessment of mastering of the theoretical knowledge \& Assessment of operational skills) $/ 2$. *, compared with the traditional group, $\mathrm{P}<0.05$.

based on the WeChat public platform to the standardized training of anesthesiology residents. Interactive teaching through the WeChat platform allows engaging activities, which facilitates educational adherence in young doctors. The cost of using the platform is negligible, and it has strong operability, feasibility and popularization potential. In addition, due to the work characteristics and the work rhythm characteristics of the department of anesthesia, it allows residents to make full use of fragmented time to learn effectively. Moreover, in addition to the real-time and efficient dissemination of anesthesia-related information, prompt communication, questions and answers, and comments are fostered in WeChat groups, which can improve the familiarity between residents, establish harmonious and friendly relationships between residents and teachers, and promote consistent educational development. Residents participating in WeChat groups can promptly resolve questions through discussion and communication. When participating in a discussion, relevant content is more profound, which is conducive to improving teaching quality. The results of this study showed that the teaching effectiveness and teaching satisfaction reported by the residents in the WeChat group significantly improved and that the assessment scores significantly improved. This change was recognized both by the residents and the teachers, which significantly improved the teaching quality.

\section{The education model based on the WeChat public platform is simple and effective model}

WeChat effectively integrates almost all media resources, such as text, voice, and video. WeChat concentrates many advantageous platforms and possess some advantages, such as convenience, sociality and openness, which makes WeChat superior to any other product (6). Furthermore, WeChat effectively facilitates face-to-face communication among people (3). By providing residents with interactive education on the WeChat platform, comprehensive internship performance can be effectively improved, which has a positive impact on teaching quality. Teachers can upload course data and video data at any time through the WeChat platform, and the residents can receive and view the above information at any time and promptly discuss related issues within the group. The participating residents can promptly resolve issues through discussion and communication. Participation in discussions reinforces relevant content, which is conducive to improve teaching quality. In addition, the WeChat platform has strong operability, popularization and timeliness, and it is easy to operate. The information provided by another participant can be received quickly, which improves communication efficiency between teachers and residents (7-9).

The education model based on the WeChat public platform is simple, which facilitates effective implementation in various specialties and hospitals. It can not only save a great deal of time but also reduce the need for classrooms and labor costs. This education model was well accepted by young doctors and achieved better teaching results.

\section{Acknowledgments}

We would like to thank the AJE (American Journal Experts) for language editing.

Funding: This work was supported by Medical Education Research Program of Shanghai Jiao Tong University (YB150732) and The Interdisciplinary Program of Shanghai Jiao Tong University (YG2015QN17).

\section{Footnote}

Data Sharing Statement: Available at http://dx.doi. org/10.21037/apm-19-390

Conflicts of Interest: All authors have completed the ICMJE uniform disclosure form (available at http://dx.doi. org/10.21037/apm-19-390). LH and GA report grants from Shanghai Jiaotong University during the conduct of the study. The other authors have no conflicts of interest to declare. 
Ethical Statement: The authors are accountable for all aspects of the work in ensuring that questions related to the accuracy or integrity of any part of the work are appropriately investigated and resolved. The protocol for the research project has been approved by Shanghai Jiaotong University, School of Medicine. All the residents have signed informed consent.

Open Access Statement: This is an Open Access article distributed in accordance with the Creative Commons Attribution-NonCommercial-NoDerivs 4.0 International License (CC BY-NC-ND 4.0), which permits the noncommercial replication and distribution of the article with the strict proviso that no changes or edits are made and the original work is properly cited (including links to both the formal publication through the relevant DOI and the license). See: https://creativecommons.org/licenses/by-nc-nd/4.0/.

\section{References}

1. Deng L, Li Y. Probe into Standardized Examinations during Residency Training. Continuing Medical Education 2010;24:3-6.

2. Hou J, Ndasauka Y, Jiang Y, et al. Excessive use of

Cite this article as: Huang L, An G, You S, Huang S, Li J. Application of an education model using the WeChat public platform in the standardized training of anesthesiology residents. Ann Palliat Med 2020. doi: 10.21037/apm-19-390
WeChat, social interaction and locus of control among college students in China. PLoS One 2017;12:e183633.

3. Wang J, Gao F, Li J, et al. The usability of WeChat as a mobile and interactive medium in student-centered medical teaching. Biochem Mol Biol Educ 2017;45:421-5.

4. Zeng F, Deng G, Wang Z, et al. WeChat: a new clinical teaching tool for problem-based learning. Int J Med Educ 2016;7:119-21.

5. Han L. The Application of Wechat Public Platform in the Field of Higher Education. Wireless Internet Technology 2015;(15):9.

6. Xiao J, Huang L. Research on Information Service Mode of the Library Based on WeChat. Modern Information 2013;33:55-7.

7. Liu L, Xiong C, Lin L. The Experimental Research on Using SMS Interactive Platform into Mobile Teaching. Modern Distance Education 2011;(3):68-72.

8. Ji J, Han Q, Liu A, et al. The Role of WeChat in Animal Surgery Teaching. Northwest Medical Education 2013;21:367-70.

9. Cui M, Huang X. Practice and evaluation of cardiopulmonary resuscitation (CPR) resident standardization training skills. Chinese Journal of Medical Education Research 2016;15:415-8. 